\title{
Males y remedios II. La evolución de la medicina en la Historia del Mundo Griego
}

\author{
Pilar Fernández UrieL*
}

A mis amigos médicos: Agustín, Eduardo, Ana, M. ${ }^{a}$ José, Joaquín, Jesús, Manuel, Fulgencio y a quienes con su esfuerzo han logrado que la medicina sea una esperanza para la humanidad.

\section{RESUMEN}

Este trabajo es un análisis de la ciencia médica en el Mundo Griego, a través de sus profesionales y de los medios utilizados (medicamentos, plantas medicinales, utensilios, etc...), en su contexto social, religioso y, sobre todo, en las circunstancias culturales e históricas en que se desarrolló la ciencia médica en la antigua Grecia.

\section{EXTRACT}

Analysis of the medical science in the Greek World, of its professionals and the means used (medicines, medical plants, tools etc...) in its social, religious context and among all, the cultural and historical circunstances in which the medical science was developed.

* Departamento de Prehistoria e Historia Antigua. UNED. 
"Reflexionamos sobre la frágil condición del Hombre y tendremos piedad sobre su suerte, pues está sujeto al azar, a los accidentes y a miles de enfermedades que amenazan su naturaleza mortal. Por ello se estima tan importante descubrir las hierbas y los remedios que pudieran ayudar al género humano".

$$
\text { PILINIO, Nat. Hist., Libro XXV, VII, } 22 .
$$

El origen de la medicina (latreía) en la cultural griega está ligada a su mitología. Son los dioses quienes inspiran a los humanos el remedio de sus dolencias ${ }^{1}$.

Los poemas homéricos citan a Peán como el dios sanador que cura utilizando sabiamente las plantas. Peán atiende a las divinidades como Hades cuando se encuentran heridas. Tal vez se trate de una antigua divinidad benéfica que fue absorbida por Apolo (Ilíada, V, 401; Odisea, IV, 232; HES., Frag. 139; SOLON, Frag. 3).

Apolo, dios del arte, la ciencia y la razón enseñó a Quirón «el más sabio, juicioso y célebre de los centauros», la medicina, junto con la música, la caza, la moral y el arte de la guerra.

Quirón fue un médico célebre que conoció el uso de las hierbas medicinales y practicó la cirugía.

Pero fue Asclepio, hijo de Apolo, quien pasó a ser el héroe y dios de la medicina.

Confiado por su padre al centauro Quirón, este enseñó al niño la ciencia y el arte de sanar, («jatrikos», término derivado del verbo «iatreuo»= ser médico), adquiriendo tal conocimiento de la misma que incluso llegó a resucitar a los muertos. Zeus, temiendo que sus conocimientos modificaran el orden del mundo, le quitó la vida con su rayo. Pero Apolo vengó su muerte abatiendo a los Cícloples.

Sus hijos fueron los célebres médicos Podaliro y Macaón citados en la lliada, también Hipócrates cuya familia pasaba por tener como antepasado al propio dios ${ }^{2}$.

\footnotetext{
Este trabajo es la continuación de otro anterior dedicado al profesor D. ÁNGEL MONTENEGRO sobre la medicina en el Mundo Antiguo: «Males y Remedios. La medicina en el Próximo Oriente y Egipto", publicado en la revista Hispania Antigua del Departamento de Historia Antigua de la Universidad de Valladolid, en su número especial en Homenaje al profesor MONTENEGRO.

2 Los médicos citados en la lliada y la Odisea tienen tanta relación con la religiosidad del momento que sus conocimientos son calificados como «divinos", inspirados por los dioses.

Así en el Canto V de la lliada, Menelao, rey de Esparta es herido por Pándaro, hijo de Licaón y es atendido por el médico, Macaón hijo de Asclepio:
} 
Es muy significativo que la medicina tenga sus más profundas raíces en las leyendas y los mitos y sus médicos se hagan descender de las más antiguas divinidades benefactoras de la humanidad.

Los médicos griegos («latroí») se relacionaban directamente con los dioses y su ciencia era una revelación divina. Como en el Próximo Oriente y en el Egipto faraónico, encontramos esta ciencia unida a la magia y a los encantamientos.

Aunque los micenólogos leen en una tablilla de Pilo, escrita en silabario Linea $\mathrm{B}$, el primer término griego relacionado con la profesión médica, hemos de esperar a los poemas homéricos, a Orfeo y Hesiodo, en los albores de la cultura griega para encontrar las primeras citas que ofrecen datos más explícitos referentes a los médicos ${ }^{3}$.

Homero les llama "expertos en remedios", que conocen muchos recursos para aliviar las dolencias. Sin embargo pocos son los datos que nos proporcionan las primeras fuentes griegas para conocer sus tratamientos.

Dos son las principales características de la medicina griega en la época arcaica:

1. La práctica de la farmacología mediante la utilización de plantas y raíces.

2. La notable y progresiva influencia de la medicina egipcia desde los primeros tiempos de la cultura griega, ya presente en los poemas homéricos:

«Entonces Helena, hija de Zeus tuvo otro pensamiento y enseguida mezcló al vino que bebían, un bálsamo que hace olvidar los pesares,

«Macaón quitó la flecha de Menelao, hijo de Atreo, al quitar la flecha, se rompió la punta. Cuando Macaón vio la herida, chupó la sangre y aplicó los medicamentos que el centauro Quiró entregó a su padre Asclepio en señal de amistad".

En el Canto XI, el aqueo Eurípilo, fue herido en un muslo por una flecha, al ser recogido por su amigo de Patroclo exclama:

«"Llévame a mi negra nave, allí arráncame la flecha, lávame con agua tibia y ponme los remedios medicinales que te confió Aquiles, gracias a las enseñanzas del sabio centauro Quirón. Nuestros médicos Podaliro y Macaón se encuentran heridos en sus tiendas y necesitan ellos también médicos que les curen las heridas" ... "sirviéndose de un puñal, el hijo de Menetio sacó la flecha de su muslo, lavó la herida con agua tibia y puso encima de la herida una raíz amarga que calmaba todos los dolores, después de trocearla con sus manos. Entonces la herida empezó a secarse y la sangre dejó de brotar"».

3 En la tablilla originaria de los archivos de Pilo (PYEq 146-9) se lee I-JA-TE = médico. Se le atribuyen unas importantes posesiones. GIL, L.: Therapeia, Madrid, 1969, también recogido por MARTínez SaURA, F.: La medicina romana, Madrid, 1996, p. 9. 
"Pementhés". Quien bebiera esta mezcla no podría en todo el día derramar una lágrima, igual si viera muertos a sus padres con sus propios ojos, que si ante él mataran con el bronce a un hermano o a un hijo querido. La hija de Zeus poseía este precioso licor porque se lo había regalado Polidamna, mujer de Thos, nacida en Egipto, tierra fértil que produce muchos bebedizos, saludable unos, mortales otros". (Odisea, IV, 220-232).

La fama de los médicos egipcios, sus medios y su ciencia fue muy grande en el Mundo Griego, el mejor testimonio son las palabras de Helena:

"Son los de allí los médicos mejores entre los hombres, pues vienen de la estirpe de Peán" (Odisea, IV, 232).

El valor de los libros médicos conservados en el templo de Ptah en Menfis era tal, que los médicos griegos iban a consultarlos aún en tiempos de Galeno.

Los tratados hipocráticos revelan la notable influencia de Egipto y Dioscórides narra muchos nombres y recursos tomados directamente de los textos médicos egipcios.

El hombre homérico no expresaba su conocimiento anatómico del cuerpo como una totalidad, pero sí mencionaba sus miembros componentes y lo describía parcialmente.

En la sociedad homérica, el médico era considerado como un artesano o «Demiurgo", es decir, una profesión liberal, no adscrita a la tierra, que iban a ofrecer sus servicios en el "Oikos» del «Basileus", pero también con frecuencia considerado como un servidor público. Podía curar las heridas («helkos»), pero también otro tipo de dolencias. Así dice el porquero Eumeo:

"¿Qué hombre de parte alguna, podría llamar a un forastero y traerlo de lejos, como no fuese de los que son útiles al pueblo: un adivino, un médico (ieter kakon $=$ curador de dolencias), un artesano que talla madera o un divino aedo que nos deleita cantando?" Odisea, Canto XVII, vV. $383-385)^{4}$.

4 Referente a esta famosa cita de la Odisea, se ha planteado un doble problema. En primer lugar la significación de los términos "leter» e «leros" homéricos. El primero sería el sanador dotado por la divinidad de dotes curativas. El segundo, sería un artesano que practicaría unos conocimientos adquiridos. VAN Brock, N.: Recherches sur le vocabulaire médical du grec ancien, París, 1961. En segundo lugar, si leter kakon significaba médico de las dolencias, es posible que ya en el mundo homérico conocía y trataba la medicina interna. AlbarRacín TeULON, A., op. cit., p. 170. También: KUDLIEN, F.: Beggin des medizinischen Denkens bei der griechen, Zurich, 1967. 
Las prácticas quirúrgicas citadas en los poemas homéricos han sido exhaustivamente estudiadas por Ch. Daremberg en el siglo pasado y más recientemente por A. Albarracín Teulón en un magnífico trabajo, ya citado ${ }^{5}$.

La época homérica y concretamente el período micénico, debido a que se desarrolló en un contexto social e histórico como sociedad guerrera, destacó la cirugía externa quirúrgica. Así Macaón y Podaliro los dos médicos, hijos de Asclepio y también los propios héroes guerreros homéricos Nestor, Patroclo, Esténelo, Agenor y Pelagonte limpian, y refrescan las heridas, arrancan las flechas de sus miembros también limpian su lesión con agua caliente, haciéndola sangrar luego, con hierbas o raíces trituradas, calman el dolor y tras vendarlas, se intenta detener la hemorragia con palabras mágicas ${ }^{6}$.

Podaliro y Macaón son calificados en la llíada de forma semejante al resto de los héroes homéricos: «insignes, valientes e irreprochables».

Como los demás héroes homéricos son también guerreros. Así dice Eúripilo a Patroclo:

“En cuanto a los médicos Podaliro y Macaón, el uno creo que está herido en su tienda y también necesita asistencia médica, el otro está entablando un duro combate..." (lliada, XI, vv. 833-836).

Es famosa la significativa frase de la llíada, puesta en boca de Idomeneo sobre la importancia de Macaón, como médico:

«Pues un médico vale por muchos hombres por sus conocimientos y su destreza en arrancar flechas y aplicar drogas calmantes». (IIIada, XI, vv. 514-515).

Aunque en una primera apariencia, los poemas homéricos parecen limitarse a describir la curación de heridas en el campo de batalla frente a

5 Daremberg, Ch.: la médecin dans Homère, París, 1865; Albarracín Teulón, A.: Homero y la medicina, Madrid, 1971. También KöRnER, O: Die ärzlichen kenntnisse in llias und Odysee, München, 1929.

6 Aunque A. Albarracín Teulón, considera que no se encuentra ni en la llíada ni en la Odisea «rasgos de significación mágico ni restos vivos de hechicería», sin embargo reconoce que los personajes homéricos atribuyen sus éxitos y sus desgracias a los dioses. Concretamente sus males son debidos a la acción de un «daimon». Además, el mismo autor cita pasajes homéricos donde la curación de heridas es acompañada con palabras mágicas que él denomina ensalmos o conjuros. Albarracín Teulón, A., op. cit., pp. 43 y 209. 
Troya, y así ha sido supuesto por muchos autores. El estudio de Artelt, completado por A. Albarracín Teulón, han demostrado el conocimiento y empleo de medicamentos internos?.

En las culturas primitivas, las mujeres, como madres, velaban y cuidaban a los miembros de la familia.

Fueron, tal vez, ellas quienes adquirieron el conocimiento de la potencia y las cualidades de las hierbas, plantas y otros elementos de la naturaleza.

En la misma época homérica ya se cita el uso de drogas y hierbas medicinales para sanar, curar, evitar el dolor y el decaimiento. Este conocimiento, muy probablemente se relacionaría con la magia y el poder divino de la Naturaleza, identificada con la propia condición de la mujer, como la Gran Madre ctónica, portadora de la vida y la tierra fecunda.

La misma mitología griega nos ofrece significativos ejemplos de heroínas y diosas, hechiceras y magas, que conocen los secretos de la Naturaleza y los utilizan: usan drogas y plantas, fabrican ungüentos, sanan y calman el dolor, e incluso realizan prodigios. Son éstas, precisamente, divinidades de condición femenina consideradas "grandes magas" conocedoras de las leyes de la Naturaleza y el Cosmos: Tetis, Deméter, Isis, Hécate y las «grandes heroínas»: Deyanira, Circe, Calipso, Medea, Hecamedes, Agamedes y Perimedes ${ }^{8}$.

Los datos referentes a medicamentos y fármacos que proporcionan los poemas homéricos son dudosos y escasos.

En su mayoría están dirigidos a calmar y curar las heridas producidas en el combate, en forma pulverizada con la doble intención hemostática y anestésica:

«Puso encima de la herida una raíz amarga que calmaba todos los dolores, después de trocearla con sus manos. Entonces la herida empezó a secarse y la sangre cesó de brotar» (Iliada, XI, vv. 846-47).

\footnotetext{
7 ARTELT, W.: Studien zur Geschichte der Begriffe «heilmittel» und "Gift», Leipzig, 1937, AlbarRacín TEULón, A., op. cit., pp. 171 y $s$.

8 Agamedes como Hecamedes son citadas en la liada como emparentadas con Hécate y Circe. Agamedes es la "experta en toda clase de pócimas y venenos que existen en la vasta tierra» Iliada, XI, 740-41. CANTARELLA, E.: Il potere femminile, storia e teoria, Milán, 1977; DeVEREuX, G.: Femme et mythe, París, 1982; HIDALGO DE LA VEGA, M. J.: «La imagen de la mujer en la magia como expresión de diferenciación de género", Homenaje al profesor Presedo, Sevilla, 1994, pp. 495-512; MAGLI, I.: Matriarcato e potere de la donne, Milán, 1978; POMERoY, S. B.: Diosas, rameras, esposas y esclavas, Madrid, 1987.
} 
Identificar esta raíz presenta una gran dificultad. Se han barajaclo varias especies de raíces con propiedades medicinales: Rhapontia, Achileia, Aristolcha e incluso la famosa hierba Moly citada en la Odisea:

«Argifontes me dio un remedio arrancando de la tierra una planta cuya naturaleza me enseñó. Tenía negra la raíz y era blanca como la leche su flor. Lámanla Moly los propios dioses, pues es desconocida y muy difícil de arrancar para un mortal» (Odisea, X, vv. 302-306).

Se citan también como recursos curativos hierbas frescas, agua, miel y sal.

Remedios y bebidas realizadas con drogas, venenos, hechizos mágicos $y$ filtros y todos se engloban en el término «Pharmakon».

Como muy bien indica A. Albarracín, «Los poemas homéricos no son un tratado de medicina". Sería un error buscar en ellos algo más que sus alusiones relativas a estas curaciones.

Pero sí contemplar los orígenes de la medicina en una sociedad que aunque heroica y mitificada, comenzaba su andadura en la historia.

Con estos primeros pasos, la medicina griega evolucionó en una gran tradición médica que nunca olvidó su origen mítico. Esculapio, padre de la medicina griega, pasaba por ser descendiente directo de Apolo, emparentado con las potencias ctónicas, señoras de la vida y de la muerte. Por ello su símbolo era la serpiente.

Fue venerado en Epidauro y en su santuario se originó una importante escuela médica, desarrollándose toda una ciencia científica en los denominados «Asclepeías», establecimientos que servían a la vez de santuario y de centro de asistencia a los enfermos que acudían para ser atendidos por los sacerdotes de Asclepio: los «Asclepiadas», que ejercían una pseudo medicina relacionada con la magia y culto a su divinidad.

El componente religioso del tratamiento del enfermo que acudía a los «Asclepeías» era fundamental.

El paciente debía cumplir ciertos requisitos previos: ofrecer sacrificios al dios y prepararse con baños, ayunos, abluciones, plegarias y otras disposiciones, más de carácter psicológicos que físico.

Una vez admitido, el enfermo pasaba la noche en los pórticos del santuario, junto a las serpientes consagradas a Esculapio y sobre la piel de la víctima ofrecida al dios que él mismo debía haber sacrificado. 
Las visiones y los sueños que el dios le inspiraba aquella noche, serían decisivos para su tratamiento, pues era interpretado por los «Asclepiadas" como el remedio adecuado decidido por el propio dios. Los sueños eran considerados como el medio más directo que tenían los dioses para comunicarse con los hombres. Ello, sin duda, aseguraba la confianza y la buena disposición del paciente.

Pero no todo consistía en efectos religiosos y psicológicos. No olvidemos que en los «Asclepeías» se prepararon generaciones enteras de médicos cuyos conocimientos se trasmitieron de padres a hijos pero también de maestros profesionales a aprendices. Los archivos, la documentación y experiencia médica que se guardaba en estos centros, sin duda contribuyó al desarrollo de la medicina griega.

En distintos puntos del Mundo Griego se consagraron escuelas de medicina, siendo las más nombradas la de Cos, Gnido, Metaponto y Crotona, además de las de Creta, Elea, Rodas, Epidauro y Efeso ${ }^{9}$.

Sin embargo, la medicina no fue en Grecia ni una verdadera profesión ni fue considerada una verdadera ciencia (Episteme), ni nada acreditaba estar en posesión de estos conocimientos, por lo que no se libró de charlatanes que desprestigiaran la profesión médica. También ocurría que un señor rico obligara a uno de sus esclavos a aprender medicina para su propio cuidado. Por ello, sabios como Platón dudaban de la profesionalidad del médico y no la consideraba como «un arte liberal» (Platón, Alcibiades, 131).

Pero hubo en Grecia verdaderos profesionales estudiosos de la medicina, surgidos de las primeras comunidades de «Asclepiadas».

La filosofía presocrática contribuyó de forma decisiva a impulsar los conocimientos de la medicina.

Los filósofos jonios se preocuparon mucho de las teorías médicas y en el siglo $v$ a.C. prestigiosos sofistas potenciaron los conocimientos médicos

9 GIL, L.: Therapeía. La medicina popular en el Mundo Clásico, Madrid, 1969; FILIPPIS, A. M.: «ll Culto di Asclepio de Epidauro a Roma. Medicina dei Templo e Medicina Scientifica, Civilita Clasica e Cristiana, 1991, n. ${ }^{\circ}$ 3, Lain Entralgo, P.: Historia Universal de la Medicina, Barcelona, 1972, pp. 70 y ss.; LóPez PIÑERo: Historia de la Medicina, Historia 16, Madrid, 1990; KuDLIEN, F.: Medical Education in Classical Antiquity, History of Medical Education, Dir. Ch. O'MaLLEY. Los Ángeles, 1970. EdelsteIn, L.: Asclepius: A collection and Interpretation of the testimonia, 2 vol. Baltimore, 1945. 
al incluir entre sus enseñanzas «el arte de la medicina», dentro del saber general y universal que todo hombre culto debía conocer, que se enseñaba bajo el nombre genérico de "Filosofía», pues "Sólo a partir de la medicina es posible conocer algo sobre la Naturaleza» ${ }^{10}$.

Ya los filósofos presocráticos (Anaximandro de Mileto, Pitágoras de Samos, Filolao y Alcmeón de Crotona) se ocuparon de los conocimientos médicos, movidos, muy posiblemente, por su interés por el cuerpo humano en su calidad de «Mikrós Kosmós».

Aunque el principal carácter del hombre era su inteligencia, analizaron su anatomía y la importancia de los órganos ${ }^{11}$.

Destaca entre ellos Empédocles de Agrigento, al que Galeno consideró como fundador de la escuela médica siciliana.

Su influencia en el "Corpus Hippocraticum» fue notable. A partir de sus trabajos, la medicina cambió en Grecia.

Heródoto cita a Demócedes de Crotona, «hijo de Califonte, que era médico y de los que, de su época, el mejor que había ejercido su profesión». Demócedes trabajó como médico público en Egina. Luego pasó a la corte del tirano Polícrates de Samos y, tras la caída de éste, fue médico particular del rey persa Darío (Heródoto, Hist., III, 125-132) ${ }^{12}$.

De esta misma escuela procedía Acmeón, al que se le considera el gran predecesor de la medicina hipocrática y el iniciador de la medicina fisiológica ( Tekné latriké»), consagrada por el propio Hipócrates y su escuela.

Fue al parecer en la escuela médica de Cos, donde surgió la medicina racional de la mano de Hipócrates, asclepiada de Cos, en torno al 460

10 Con este criterio se formaba a los jóvenes a la vez, sabios y sagaces para desenvolverse en la vida. Con ello se lograba la «areté», es decir, el conjunto de cualidades de un varón, no sólo morales sino intelectuales, concepto semejante a la "virtus» latina. MARrou, H. l.: Historia de la educación en la Antigüedad, Madrid, 1960, p. 65; GıGón, O.: Der Ursprung der griechischen Philosophie von Hesiod bis Parmenides, Basilea, 1945.

11 Estos primeros estudios han sido recogidos por DIELS, H.: Doxographi Graeci, 6. Ed. por W. Kranz, Berlín, 1951; Jones, W. H. S.: Philosophy and Medicine in Ancient Greece, Baltimore, 1946. También: OleRUd, A.: L'idée de microscosmos et macroscosmos dans f.e Timée de Platon, Upsala, 1951. Sobre los estudios de anatomía: EdELSTEIN, L.: "The History of Anatomy in Antiquity", Ancient medicine. Selected Papers, ed. O. TEMKIM y C.L. TEMKIM. Baltimore, 1967, pp. 247-301.

12 Otros famosos médicos anteriores a la medicina hipocrática fueron Eurifonte, Ctesias y Polícrito de la escuela de Cnido y Nebro de Cos. 
a.C., al que se le considera tradicionalmente como padre de la medicina. Inició un método, que saliendo del empirismo, basaba sus conocimientos médicos en la observación y el raciocinio.

Analizó y escribió la historia clínica de las enfermedades, anotando síntomas, síndromes y evolución, sin que estas anotaciones hayan perdido actualidad ${ }^{13}$.

Sin abandonar del todo su vertiente religiosa, las enfermedades fueron tratadas como un fenómeno natural y no exclusivamente como un castigo de los dioses.

En las escuelas médicas, los maestros profesionales se rodeaban de ayudantes y aprendices.

Apenas sabemos sobre la ciencia hipocrática que se encuentra recogida en el famoso tratado de la "Antigua medicina" y en los "Aforismos" que forman el "Corpus Hippocraticum" ${ }^{14}$. El Corpus Hippocraticum comprende, pues, un conjunto de tratados médicos que se recopiló en la Biblioteca de Alejandría, de los que nos han llegado cincuenta y tres.

La medicina hipocrática no sólo se preocupó de la enfermedad sino también del enfermo, considerado además de centro de su investigación médica, en su vertiente humana.

El hombre era el «Metron», el centro y medida de sus investigaciones (siguiendo fielmente el espíritu del pensamiento griego), magníficamente expresado por Platón:

13 De Hipócrates sabemos que posiblemente era originario de Cos, o al menos se formó en su escuela médica, hacia el 460 a.C. Según la tradición su primer maestro fue su propio padre, el médico Heráclidas del que también aprendieron sus hermanas Higea y Panacea. Fue discípulo de Heródico de Selimbria. Se relacionó con los filósofos Demócrito y Górgias. Ejerció la medicina en el norte de Grecia, Tasos y Ponto Euxino. Gozó de una importante fama que aumentó tras su muerte, en Larisa que, envuelta en leyenda, se le atribuye a los 104 años. Se contaba que sobre su tumba, las abejas labraron una colmena cuya miel tenía virtudes curativas. Aristóteles le calificó como el más grande médico y Galeno le llamó «el divino inventor de todo bien». La cultura occidental le ha consagrado como el "padre de la medicina». Sobre Hipócrates y su influencia en la medicina griega hay una abundante bibliografía, la más reciente: LAIN ENTRALGO, P.: La medicina hipocrática, Madrid, 1987. También ver entre otros: FenstugIÉRE, A. J.: Hippocrate. L'ancienne médecin, París, 1948. KudLIEN, F.: Der Beggin des medizinischen Denkens bein Griechen, Zurich, 1967. Martiny, M.: Hippocrate et la médecin, París, 1964. AlsinA, J.: «Sobre la medicina hipocrática", Estudios clásicos, XIII, 1969, JoLY, R.: Le niveau de l'Science hippocratique, París, 1966.

14 Ver los textos: Tratados Hipocráticos, de la colección Gredos, dir. por Carlos García Gual, Madrid, 1990. 
«El enfermo es amigo del médico, por tanto confía en él, se entrega a él, pues es su esperanza a causa de su enfermedad" (Platón, Lisias, 217-a).

En tal sentido, el médico hipocrático conoció y practicó la psicoterapia. Conoció la importancia de la actividad psíquica y utilizó el ánimo y la confianza del enfermo y su influencia sobre el cuerpo. Así dice el autor del tratado hipocrático «Sobre la decencia»:

«El médico procederá con calma, con habilidad, ocultando al enfermo, mientras actúa, la mayor parte de las cosas que perjudiquen su ánimo, exhortándole con alegría y serenidad... o reprendiéndole con vigor apacible o consolándole con atención y buena voluntad».

El médico también necesita la colaboración del enfermo, tanto en la predisposición de su propia naturaleza («Phisis»), como en su obediencia, alcanzada por esa confianza entre ambos y la misma sabiduría y disposición del médico con sus cuidados y servicios («therapeía»).

El verdadero médico como profesional busca un medio de vida y prestigio, pero también, siente vocación por una ciencia y un arte por la naturaleza a la que "ha de salvar sin cambiar» y sobre todo, al hombre como centro de la misma.

Toda esta ética y concepto de la medicina griega («Philotekné»), se expresa de forma admirable en el juramento hipocrático que no ha perdido un ápice de su calidad humana a través de los siglos y sigue reflejando la ética y la profesionalidad que guía la conducta del médico:

«Nunca daré veneno a nadie, aun cuando me lo pidan; nunca daré a una mujer drogas apropiadas para hacerla abortar; en cualquier casa que entre, iré a ella para la salvación de los enfermos, absteniéndome de toda injusticia $y$ de todo daño voluntario" ${ }^{15}$.

No es de extrañar que se considerara a la medicina un origen o don de los dioses y que sus profesionales estuvieran bajo su protección. Recordemos a quienes se destinaba y consagraba el Juramento Hipocrático:

15 EldesteIn, L.: The Hippocratic Oath: Tex, translation and Interpretation, Baltimore, 1943; KUDLIEN: «Medical Ethics and Popular Ethics in Greece and Rome», Clio Medica, n. ${ }^{\circ}$ 5, 1970, pp. 92-121; GIL, L.: Therapeia. La medicina popular en el Mundo Clásico, Madrid, 1969. 
«Juro por Apolo médico, por Asclepio, Higieia y Panacea, así como por todos los dioses y diosas, poniéndolos por testigo dar cumplimiento en la medida de mis fuerzas y de acuerdo con mi criterio a este juramento de compromiso".

El médico hipocrático seguía tres principios fundamentales:

1. Favorecer o no perjudicar. Ser útil sin daño.

2. Abstenerse de lo imposible. Evitar molestias inútiles al paciente.

3. Atacar la causa del daño a través de sus conocimientos técnicos.

Estos conocimientos eran fundamentalmente el estudio de la Phisis o conocimiento de la Naturaleza y del hombre como su centro y medida.

Los conocimientos de anatomía humana eran muy deficientes, debido a la prohibición moral y religiosa de diseccionar los cadáveres, por lo que las prácticas se realizaban sólo con animales. El propio Aristóteles expone con importantes fallos sus conocimientos de anatomía.

Tampoco la práctica quirúrgica estuvo muy desarrollada. No hubo cirujanos puros ni especialistas en cirugía que sin embargo se encuentra ampliamente citada y contemplada en el "Corpus Hippocraticum».

Tanto las fuentes históricas como los hallazgos de instrumentos médicos revelan la práctica de operaciones manuales: sangrias, aplicación de clísteres, de forceps y de ventosas en ginecología (de asta y de bronce), bisturís y pinzas.

Mención especial merece lo que los griegos calificaban como «la enfermedad del alma», es decir, la locura que diferenciaban de las enfermedades corporales. No sólo eran enviadas por la divinidad, podían ser la manifestación directa del dios que poseía al enfermo (Manía divina) ${ }^{16}$.

Aunque un espíritu "daimon» o cualquiera de los grandes dioses del panteón griego podía ser el causante de esta enfermedad, la principal responsable era Ate hija de Zeus, personificación del error. Ate engañó a su padre Zeus y por ello, le fueron cerradas las puertas del Olimpo. Desde entonces Ate erraba triste, posándose en la cabeza de los mortales.

16 Sobre el estudio de la «posesión divina» en Grecia ver: H. JeANMAIRE, Dionysos, París, 1951. También: Martínez PINNA, J.: «La comunicación con la divinidad», Historia $16, \mathrm{XV}, \mathrm{n} .^{\circ} 166$, pp. 64-72. 
Así dice Agamenón:

"¿Qué podía yo hacer? Una divinidad de todo es responsable, la hija mayor de Zeus, Ate, que a todos nos manda el vértigo (lliada, XIX, 86-96).

Ya en los textos homéricos, la locura era considerada como un mal sagrado y como tal era tratado también en la medicina hipocrática.

Este tratamiento se iniciaba buscando el origen y el causante de la posesión, analizando la conducta del enfermo (melancolía, violencia, rugidos, sonambulismo, delirios...), tales síntomas se relacionaban con los caracteres de tal o cual divinidad.

Tras ello, se realizaba un diagnóstico y se buscaba reconciliar al paciente con la divinidad posesora para apaciguarla.

Este remedio resultaba ser homeopático, porque consistía en sustituir una posesión por otra, a través de purificaciones, encantamientos, prohibiciones alimenticias, también ritos de purificación. En realidad se trataba de un tratamiento psicológico de persuasión del paciente, con grandes dosis de sugestión psicológica, como es en muchos casos la psiquiatría.

Los fármacos siguieron considerándose en el triple concepto de medicamento, veneno y como recurso netamente mágico y religioso.

Sin embargo, sí se modificó su acepción como sustancia exterior del cuerpo que podía ejercer sobre éste una modificación u acción, interior o exterior.

En farmacología, la medicina hipocrática cita numerosos medicamentos, muchos de ellos ya utilizados por la medicina babilónica y sobre todo egipcia. Muchos de ellos están elaborados a base de raíces y plantas medicinales manejadas por expertos: el «rizótomo» y el «farmacópolo», que también utilizaron drogas ${ }^{17}$.

17 Se utilizaron entre otras: anémona, menta, eléboro, hisopo, salvia, tilo, mandrágora... También otras substancias naturales como la sal, vino, miel, minerales o productos animales... Fueron administradas de diversas formas: píldoras, clísteres, infusiones epítimas, eclegmas, fumigaciones. Tenían diversos efectos: purgantes, eméticos, diuréticos, narcóticos, emolientes, diaforéticos, etc. Ver Losa-Rivas-Muñoz MEdina: Botánica descriptiva. Granada, 1974. STUART, M.: Enciclopedia de hierbas y herboristería. Barcelona, 1981. FonT QueRR, R.: Plantas Medicinales: Dioscórides renovado, Barcelona, 1976. Sobre la aplicación de los fármacos en la medicina hipocrática: JolY, R.: Recherches sur le traité pseudohippocratique. Du régime. París, 1960. 
Pero también los mismos médicos preparaban las drogas que proporcionaban a sus enfermos.

La sofística y la educación griega estuvieron relacionadas con la medicina y la farmacología de la Grecia clásica.

La importancia y la propia afición de los helenos a los ejercicios corporales, siempre presentes en la educación y en la vida griega exigieron que el "pedotriba" o maestro de los ejercicios corporales de los gimnasios adquiriera los conocimientos más esenciales de medicina que practicaba con los atletas (higiene, dietética, masajes y nociones de traumatología). Platón cuenta que muchos de ellos llegaron a ejercer la medicina (Platón, Repub., III, 406-a-b).

Así como éstos eran los "médicos de los gimnasios", también había médicos dedicados a los militares que asistían a los ejércitos en las batallas.

Platón en sus «Diálogos» (La República, Cármides, El Político y Las Leyes), describe el ejercicio de la medicina en la Atenas del siglo IV a.C. Si seguimos su testimonio habría una medicina para esclavos, y una medicina para ricos y otra para pobres. Sin embargo, otros testimonios recogidos del propio Platón y de los textos hipocráticos («Sobre la Dieta») presentan una visión menos cruel y caricaturizada del ejercicio de la medicina.

Âl fin y al cabo sabemos que en Atenas, los médicos públicos "(Demonios latros") eran elegidos en la Eklesía o asamblea de ciudadanos, tras analizar los títulos y los méritos de los candidatos. De esta forma, también eran elegidos otros oficios públicos.

Estos «médicos públicos» tenían la obligación de asistir a los ciudadanos que no podían costearse un médico particular. Los gastos que acarreara su curación también eran absorbidos por el Estado. Todos estos dispendios se costeaban a través de un impuesto especial («latricon»).

«... Me refiero al hecho de poder, mediante discurso ante la Eklesia, ante los miembros de la misma..., y en verdad que con este poder se obtiene que tendrás al mejor médico como tu servidor y como servidor al mejor maestro de gimnasia...». (Platón, Gorgias, 455b).

Muchos de estos médicos prestaron excelentes servicios en su ciudad. Sus conciudadanos en prueba de su agradecimiento les dedicaron inscripciones honoríficas que han permanecido como testimonio valiosísimo y 
de primera mano que informan al historiador sobre el ejercicio de la medicina en la Grecia clásica ${ }^{18}$.

Los médicos podían ejercer libremente su profesión, recibiendo en sus casas a los enfermos («latreion»). También había médicos ambulantes que iban por los lugares ofreciendo sus servicios.

Más adelante hubo médicos que sirvieron en la corte de los reyes helenísticos en Antioquía como Erasístrato y en Alejandría, como los médicos de los soberanos Lágidas.

Está atestiguada la existencia de mujeres que ejercían la medicina («latriné»). Es posible que su actividad se limitara a entender a los pacientes de su propio sexo, en particular como parteras o en ginecología («maía», Maieutría»).

Así la nodriza de Fedra dice a su ama:

«Si sufres de un mal que no se debe decir, tienes aquí a mujeres que te ayudarán a calmarlo; si es un accidente que se pueda revelar a los hombres, habla, para que tu caso sea señalado a los médicos" (Euripides, Hipólito, vv. 293-296).

Aunque la existencia de un término propio para la mujer, permitía sugerir que su actividad fuera más amplia. Sin embargo, en la Atenas clásica se prohibió a la mujer ejercer públicamente la medicina, como otras muchas actividades. Es famosa la figura de Agnódice que ejerció la ginecología disfrazada de varón. Acusada de seducir a sus pacientes, demostró su condición de mujer ante el tribunal del Areópago y se le concedió seguir practicando libremente a causa de sus éxitos.

Sin embargo los tratados ginecológicos griegos que se conservan están escritos por hombres.

Es posible que estas limitaciones se suavizaran en el período helenístico, pero los testimonios que nos revelen el ejercicio femenino de la medicina son escasos y dudosos. Merece mención Antioque de Licia, del siglo I a.C. cuya profesionalidad está acreditada por la epigrafía y por su relación con otro médico, Heráclides de Tarento.

18. Sobre los «médicos públicos» ver: CoHn-HAFT, L.: The Public Physicians of Ancient Greece, Northamton, Mass., 1956; también JoLY, R.: «Esclaves et Médecins dans la Grèce antique». Sudh. Arch., 53, 1969. 
Fuera del tratamiento de las escuelas de medicina, los pacientes cayeron en manos de charlatanes y quienes practicaron una "brujería curativa", que ya se remontaba a la época arcaica y que perduró en el período helenístico.

Dice F. Kudlien que si hay un período en la medicina antigua que se diferencia claramente del anterior ese es el helenístico.

Llegando a este período, es importante señalar que la medicina sufrió las mismas vicisitudes y circunstancias históricas que la ideología y la cultura de su propia época.

Tras el durísimo paréntesís de la Guerra del Peloponeso (431-411 a.C.), que asoló el Mundo griego, éste surgió a la Historia con unas perspectivas diferentes. No sólo la sociedad y la economía sufrieron un durísimo golpe. Los valores y la visión ante la vida no volvieron a ser los mismos. Las mentalidades también se conmocionaron. Los ideales tradicionales ya no valían. Las divinidades poliadas habían defraudado a los ciudadanos que buscaron otros dioses o al menos, otras ilusiones.

No es de extrañar que la visión del griego hacia su ciencia y hacia su propia cultura cambiara. Su filosofía y su concepto de la ética y de la propia naturaleza se modificó. Recordemos el famoso y significativo proceso de Sócrates que marca un hito en la vida y la mentalidad griega.

La medicina también fue hija de su tiempo e igualmente manifiesta estos cambios a través de las actitudes, la confusión y la división en las distintas escuelas de medicina que surgen a partir del siglo IV a.C. y el período helenístico ${ }^{19}$.

La medicina helenística refleja las transformaciones particulares de su propia cultura: su complejidad y diversificación, las fluctuaciones que también se manifiestan en otras facetas de la vida griega en el arte, en el pensamiento, en la religión y en la propia sociedad. Necesariamente tuvieron

19 Sobre el periodo helenístico: VAzQUez Hoys, A. M.a: Introducción a la Historia Antigua II. El Mundo griego, t. II: El siglo N a.C. Alejandro Magno. El helenismo, Madrid, C.U.,1993; sobre la religión en la época helenistica: FESTUGIÊRE, A. J.: La vie spirituelle en Grèce à l'èpoque hellenistique, París, 1977; sobre la ciencia en este período: CromBIE, A. C.: Scientific Changes: Symposium on the History of Science. University of Oxford, 9-15, july, 1961, Londres, 1963; BARNES, J.; Brunschwing, M.; Buryeat, M.; Schofield, M. eds.: Science and Speculation: studies in Hellenistic Theory and Prectice, Cambridge-París, 1982; Hodges, H.: Technology in the Ancient World, Harmondsworth, 1970; Neugebauer, A.: The technical Arts and Sciences of the Ancients, Londres, 1969. 
que revelarse en otros aspectos de esta civilización como era la ciencia médica donde se sucedieron grandes contrastes, momentos de letargo y estancamiento, a la vez que brillaron importantes médicos científicos que dieron un gran empuje a conocimientos tan decisivos como la anatomía humana, el concepto de Naturaleza y del hombre como su objeto principal. Por ello, siguió siendo notable y decisiva la influencia de la filosofía ${ }^{20}$.

Se continuaron escribiendo tratados bajo el nombre de Hipócrates que se incorporaron al "Corpus Hippocraticum" como los tratados «Sobre el régimen» (Perí Trophés) y «Sobre el corazón» (Perí Kardies) considerados de este período ${ }^{21}$.

Sin que los antiguos centros griegos perdieran su prestigio y actividad como Cos, Epidauro y Gnido, el centro científico de la primera medicina helenística fue Alejandría. Médicos como Diocles de Caristo (340-360 a.C.), su discípulo, Praxágoras de Cos, Herófilo de Calcedonia y Erasístrato de lulis que trabajaron en la corte de Alejandría, dieron un gran impulso a los conocimientos anatómicos, a las funciones de los órganos del cuerpo y a su reacción ante las enfermedades (fiebre, pulsaciones), investigaron sobre el sistema nervioso, la circulación sanguínea y la utilización de los medicamentos ante las enfermedades ${ }^{22}$.

Ellos lograron que la medicina post-hipocrática y post-aristotélica tuviera una perspectiva diferente.

\footnotetext{
20 LLoID, G. E. R.: Medicine. An Illustrated History, Nueva York, 1978.

21 JOLY, R.: Recherches sur le traité pseudohippocratique Du régime, Paris, 1960; KUDLIEN, F.: «Pseudo-Hipocrates: "Peri Kardies", en Hernes, 90, 1962, pp. 424-427.

22 Herófilo descubrió los nervios raquídeos, las meninges y otras partes del cerebro como la formación venosa que aún se denomina "prensa de Herófilo" y diferenció el cerebro y el cerebelo, considerando el cerebro como centro de la mente, además distinguió los nervios sensitivos de los motores. También descubrió los ventrículos centrales con sus plexos, sobre todo el cuarto ventrículo, analizando las arterias y la misión del corazón en cuya anatomía profundizó Erasístrato. También analizó el hígado que describió con gran detalle, y los vasos sanguíneos conectados con él, el páncreas, el duodeno y parte del aparato genital femenino. Ambos médicos lograron estos importantes avances en el conocimiento de la anatomía humana debido a su estudio no sólo sobre cadáveres sino con la práctica de la vivisección, realizada con criminales proporcionados por los soberanos Ptolomeos. Algo que repugnaba a la ética y pensamiento griego. Ver Martínez Saura, F.: La medicina romana. Desde la perspectiva de "De medicina» de A. Cornelio Celso. Madrid, 1996, pp. 30-31; Allbut, C.: Greek Medicine in Rome, Londres, 1921; GorTeman, Cl.: «Medicins de Cour dans l'Egypte du III' siècle avant J. C.", Chronique d'Egypte, XXXII, 1957, pp. 313-336; Peremans, W.-VAN'T DACK, E.: Prosopographia Ptolemaica, VI, 1968, núms. 16.57116.651; VÁZQUEZ HoYs, ANA M..: Introducción a la Historia Antigua II: El Mundo griego desde el siglo N. Alejandro magno. El helenismo, Madrid, 1993, pp. 650-654.
} 
En Alejandría a la vez se aunó y se enfrentó la milenaria sabiduría egipcia y la ciencia griega.

Si por una parte, el conocimiento egipcio aportó al carácter científico de la medicina alejandrina su interés por el estudio de la anatomía humana, también en Alejandría se produjo la rivalidad entre griegos y egipcios manifestado en los perjuicios culturales entre unos y otros y las tensiones sociales que acabaron con la expulsión de los intelectuales griegos, incluidos los médicos de Alejandría en el año 144 a.C. ${ }^{23}$.

Su diáspora fue una de las principales causas de la formación nuevos centros o escuelas médicas derivadas de la de Alejandría como la de Laodicea fundada por Zeuxis y la de Esmirna fundada por Hicesio.

A partir del siglo III a.C., tanto el saber como el ejercicio de la ciencia médica se hallaba disgregado y dividido en sectas o escuelas debido a varias causas:

- Tanto Herófilo como Erasístrato habian formado y trasmitido su ciencia a una gran cantidad de discípulos que no siempre siguieron unas mismas pautas y el mismo camino que sus maestros.

- La rápida evolución del conocimiento científico impuso un período o paréntesis de reflexión e incluso de retroceso que Doss califica como «miedo a la libertad intelectual», en una época donde sobresalían los prejuicios religiosos y culturales ${ }^{24}$.

- A partir del siglo IV a.C., una serie de factores influirian notablemente en el pensamiento y la cultura:

* La filosofía cínica y sobre todo estoica pesaron fuertemente en la ética, la religiosidad y el conocimiento científico. Se consideraba la superioridad del alma sobre el cuerpo al que se despreció y por lo tanto no se consideró su cuidado y conocimiento. Este pensamiento tuvo una gran repercusión en las religiones helenísticas denominadas «Mistéricas» 0 «De Salvación", entre ellas, el cristianismo ${ }^{25}$.

23 Saunders, J. B. de C. M.: The Transitions from Egyptian to Greek Medicine", Kansas, 1963.

24 Doss, E. R.: The Greeves and the Irrational, Berkeley-Los Angeles, 1964, Tratado en el cap. VIII.

25 Sobre las relaciones entre la antigua ciencia médica y el cristianismo primitivo: Schadewalt, $H .:$ "Arzt und Patient in Antiker und frühchristlicher Sicht», Medizinische Klinik, 1964, n. ${ }^{\circ}$ 59, pp. 146-152. 
* Estas religiones de salvación y la afición por los métodos de carácter mágico-religioso contribuyeron a infravalorar el conocimiento científico y experimental.

A la luz de todas estas circunstancias entenderemos la división, e incluso a veces, la anarquía que caracterizó la medicina helenística.

Como indica F. Martínez Saura, es preciso aclarar que la diferenciación de las escuelas médicas, se encuentra más en el plano teórico y conceptual que en el práctico pues «se aplicaron los mismos tratamientos en las mismas enfermedades» ${ }^{26}$.

- La primera escuela médica del helenismo fue la denominada Empírica, fundada por Filino de Cos, discípulo de Herófilo y Serpio de Alejandría.

Filino rompió con las enseñanzas de su maestro y reaccionó contra la medicina científica y contra la investigación anatómica sistemática.

Tal vez en la formación de esta escuela se hallaba soterrada una reacción moral y social contra la disección de cadáveres y sobre todo la repugna que provocaron las vivisecciones realizadas por Herófilo y Erasístrato ${ }^{27}$.

Se argumentó vénementemente que la condición de los cadáveres eran completamente diferentes a los vivos y por lo tanto la visión del interior de los cuerpos era inutilizable a la medicina. Además consideraban el estudio de la anatomía y la fisiología era inservible porque la Naturaleza era insondable y no podía conocerse. Sólo era válida la experiencia ${ }^{28}$.

Una segunda característica de esta escuela fue su veneración por la medicina hipocrática que culminó con la divinización del propio Hipócrates.

26 Martinez Saura, F., op. cit., p. 26.

27 Este experimento siempre fue criticado por su crueldad y por la repugnancia que provocó incluso en épocas posteriores. El propio Celso lo recuerda con estas palabras: «Pienso que es a la vez inútil y cruel abrir cuerpos vivos, pero es necesario a los que cultivan la ciencia dedicarse a la disección de cadáveres». Celso, Proem., 73).

28 Para esta escuela, la medicina se clasificaba en semiótica, terapéutica e higiene. Glaucias de Tarento, uno de sus principales representantes, en el siglo ॥ a.C. puso los principios de esta escuela en el que denominó «trípode empírico»: formado por los «empiria» u observaciones propias, la historia o aplicación de lo observado y la analogía o utilización de lo icual por lo igual. MARTíNEZ SAURA, F., op. cit., p. 27; sobre la escuela empírica ver también: STOK, F.: «La scuola medica Empirica a Roma", Auftieg und Niedergang der Römischen Welt, Berlín, 1993; DEIGHGRAEBER, K.: Die griechishe Empirikersschule, Berlín-Zurich, 1965. 
Los textos hipocráticos fueron uno de los principales objetos de investigación en la Biblioteca y el Museo de Alejandría.

Estas importantísimas instituciones recogieron el enorme bagaje cultural acumulado y fueron centros de investigación y estudio de las ciencias, entre ellas la medicina.

Concretamente, en el campo de la medicina se produjeron distintos tipos de reacciones, ciertas especializaciones y sobre todo se separó el estudio teórico del ejercicio práctico, llegándose a una exagerada tendencia a valorar la teoría y estudio de la medicina por encima de su práctica. Los discípulos de Erasístrato y sobre todo de Herófilo llevaron tales tendencias a su máxima aplicación en las escuelas definidas por Galeno como «escolásticas»: Metódica y Dogmática ${ }^{29}$.

Sin duda Erasístrato y Herófilo pretendieron hacer una medicina científico-cultural, valorando lo imprescindible la parte teórica.

El médico debía tener en la sociedad la reputación de un hombre culto, un médico filósofo, en el concepto que la cultura griega daba a este término.

Pero la actitud de estas escuelas "escolásticas» llevaron esta norma a una postura extrema, apegada a los dogmatismos, definiciones y dialécticas que ni eran o ni verdadera ciencia ni «verdadera filosofía», rechazando o relegando la profesionalidad científica del médico y su acción humanitaria ante el enfermo.

Conocemos por Celso las diferencias entre ambas escuelas. sobre la Dogmática afirma:

"Los partidarios de la medicina racional empiezan sentando como principio que el médico debe conocer las causas ocultas y próximas, luego, las causas visibles de las enfermedades, después las acciones naturales y en último lugar, las estructuras de los órganos... (Celso, Proem., 14, sig.).

Describe la doctrina de la escuela Metódica en los siguientes términos:

29 «Comentar por comentar, haciendo ostentación de una alambicada pedantería y al mismo tiempo sin tener ideas propias ni verdaderas, ésta es una de las características más significativas del letargo escolástico al que nos referimos". Así son definidas por F. Kưdien: «Medicina helenística y helenístico romana», en Historia Universal de la medicina, Dir por Lain Entralgo. Vol. II, Barcelona, 1972, p. 166. 
«... No quieren ser incluidos ni entre los dogmáticos ni entre los empíricos, para ellos, el conocimiento de las enfermedades está fuera del arte médico que se encuentra limitado a la práctica. Aún son inferiores a los empíricos ya que éstos tienen en cuenta en su examen muchos detalles, mientras que los metódicos se limitan a una observación parca y vulgar. Así, pues, actúan como los veterinarios...» (Celso, Proem., 65 y sig.) ${ }^{30}$.

A comienzos del siglo I a.C. surgió una nueva escuela médica, tal vez desgajada de los metódicos, con la que la medicina parece despertar de este letargo.

Esta nueva escuela se formó también de la mano de la Filosofía, concretamente de las enseñanzas de la llamada «Stoa Media», cuya doctrina arrancaba precisamente de la filosofía tradicional. Uno de sus más destacados maestros era Posidonio de Apamea, cuyo discípulo Ateneo de Atala fundó la escuela Pneumática, así denominada por considerar al «Pneuma» = aire, soplo de viento, como elemento corporal tanto externo como interno o estado anímico y por lo tanto considerado como el eje de la vida.

El «Pneuma» era el centro de sus estudios fisiológicos y patológicos.

Si la visión del mundo de las doctrinas de Posidonio de Apamea consideraba que la Naturaleza, tanto macrocósmica como microcósmica estaban dominadas por el concepto central de "simpatía", significando este término la interdependencia de todos los fenómenos cósmicos, el «Pneuma» era el centro impulsor de la vida en el hombre considerando a éste como un «Mikrós Kosmós" siguiendo el antiguo concepto filosófico del hombre como centro e imagen de la propia Naturaleza ${ }^{31}$.

El antiguo texto hipocrático del Anónimo Londinense, «Sobre el viento» (Peri Physon), comprende en gran medida el espíritu de la doctrina peumática, pues define al aire "como el factor de mayor importancia en el estado de la salud y la enfermedad, junto a los humores del cuerpo» ${ }^{32}$.

Añaden a ello los pneumáticos un estudio más preciso del «Pneuma» que tomaron de la filosofía estoica y más concretamente en las doctrinas de Posidonio, haciendo un paralelismo constante entre el Makrós Kosmós

30 Sobre la medicina metódica: MEYER-SteInEG, TH.: Das medizinische System der Methodiker, Jena, 1916; EdelsteIn, L.: «The Metodists», Ancient Medicine, ed. O. y L. TEMKIM, Baltimore, 1967, pp. 173-191.

31 KudLien, F.: «Art. Pneumatischen Arzte», en Pauly Wissowa R.E. Suppl. XI, 1968.

32. JONES, W. S. H.: The medical writtings of Anonymus Londinenesis. Cambridge, 1947. 
y el Mikrós Kosmós. Así, la fisiología del «Pneuma» de estos médicos se basa en diferenciar el «Pneuma exterior» del «Pneuma interior» al que, a su vez, diferencian en distintos matices: innato, anímico, etc. ${ }^{33}$.

Consideraban al corazón el órgano central y centro del calor innato y del "Pneuma» vital, esto produjo un gran retroceso en su conocimiento anatómico y fisiológico humano. Estos médicos, influidos por la filosofía de Posidonio, de corte estoico, dieron una gran importancia al cuidado del alma, concebida como fuerza espiritual y constante frente a la materialidad, debilidad y perdurabilidad del cuerpo.

Es significativo que los médicos de la escuela pneumática hablaran de la «Limpieza del alma y el barro del cuerpo» y que se ocuparan de forma especial y primordial de la terapia física especialmente de la balnoterapia. Su postura científica e intelectual fue recogida por la medicina paleocristiana en época Imperial romana.

Contemporáneo de Ateneo de Atala fue Asclepiades de Bitinia, figura compleja y polémica, situada entre la medicina helenística y la romana.

Su propia personalidad aparece equívoca y confusa ante el historiador. Fue una de las figuras intelectuales más sobresalientes del final del helenismo. Sin embargo, Plinio el Viejo, cien años más tarde cita a Asclepiades de forma embrollada y tal vez errónea, calificándole de charlatán y embaucador. Pero cada vez parece más seguro que su personalidad fuera confundida con el orador Asclepiades de Mirlea ${ }^{34}$.

Asclepiades revivió la filosofía escéptica, existente como tal en torno al 300 a.C., provocando no sólo un nuevo auge de esta filosofía, sino una renovación de la ciencia médica.

Siguiendo la teoría de Epicuro, según la cual el espacio estaba compuesto de átomos, el cuerpo humano, como parte integrante del mismo, también se componía de estas partículas que se encontraban en continuo movimiento y en constantes cambios.

Esta teoría le valió explicar la génesis de las enfermedades internas y desarrollar su patofisiología. La salud se hallaba en la simetría, es decir en

\footnotetext{
33 Ver Kudlien, F., op. cit., p. 172; también López Piñero, J. M.: Historia de la medicina, Madrid, 1990.

34 Scarborough, J.: «The Drug Lore of Asclepiades of Bitinia», Pharmacy in History, 17, 1975, pp. 43-57.
} 
la justa coherencia de los átomos que forman el cuerpo humano. Por el contrario, la enfermedad se producía por la «atonía» o situación anormal de éstos que provocaban la pérdida de la salud.

A Asclepiades se le debe la renovación de la medicina en múltiples aspectos, como la promoción de la medicina interna y la contemplación y atención humana al paciente.

Además de las escuelas de medicina, las diversas fluctuaciones más o menos acertadas de los médicos y los altibajos en el desarrollo de la ciencia médica en el período helenístico, no quisiera acabar sin citar otros aspectos de la ciencia médica no menos importantes y que tuvieron una gran repercusión en la medicina romana posterior. Me refiero a los avances en la cirugía, la ortopedia y los aparatos médicos y la farmacología.

La cirugía fue una de las principales especialidades de la medicina griega y helenística, hasta tal punto que había tomado un camino propio casi separada del resto de la práctica médica. Es posible que ello se debiera a una doble causa:

- Su desarrollo había sido considerablemente superior al resto de las especialidades médicas, muy posiblemente debido a la influencia de la medicina egipcia.

- El carácter extremadamente teórico del resto de la medicina en las escuelas helenísticas.

Filoxeno de Alejandría en el siglo II a.C., escribió el primer manual completo de cirugía operativa que fue utilizado por Celso y parece que está incluido en el tomo séptimo de su famoso tratado «De Medicina».

Conocemos por los relieves los hallazgos arqueológicos y las descripciones literarias, entre las que sobresale sin duda la ofrecida en el citado Libro VIl del tratado de Celso, los instrumentos utilizados en cirugía.

Sorprende el grado de diferenciación, especialización y refinamiento de los aparatos y el delicado instrumental utilizado por los cirujanos de esta época: trépanos, escalpelos, sierras, tenazas, pinzas y distintas clases de cuchillos de diferentes formas y medidas, además de forceps, ventosas, espejos vajinales utilizados en ginecología, sondas, cucharas, cánulas, grapas para las heridas, todo ello cuidadosamente manejado y preparado por enfermeros especializados.

Algunos cirujanos helenísticos se dedicaron a una especialización concreta en el campo de la cirujía como Amonio que se dedicó a las cisetomías recibiendo por esto el nombre de Lithomos. 
El auge que en el helenismo cobraron la fabricación de maquinaria e inventos para distintas utilizaciones fue aprovechado por la medicina, especialmente la ortopédica.

Sus aparatos y mecanismos eran manipulados y aplicados por especialistas llamados «organikoi» (quienes utilizaban aparatos mecánicos eran denominados «mekanikoi»).

Éstos no sólo sabían manejar los aparatos ortopédicos, sino que ayudaban a los médicos a utilizar el instrumental quirúrgico y colaboraban en el tratamiento de los enfermos. Podían compararse a los enfermeros especializados.

La farmacología aumentó considerablemente sobre todo en el conocimiento de drogas y plantas posiblemente por el contacto con Oriente tras las conquistas y las exploraciones y estudios impulsados por Alejandro Magno.

Ya Erarístrato había escrito un tratado sobre los peligros y efectos de las drogas. Pero fueron sobre todo los empíricos quienes enriquecieron la farmacología helenística interesándose por los venenos y sus antídotos.

Más tarde Teofrasto ofrece un estudio más amplio de esta materia.

Entre las drogas utilizadas figura el opio recomendado contra el insomnio, el cólico y la hidrofobia.

En las recetas de la época se utilizaba el vino, la miel, la sal y las especies como la pimienta, el cinamomo o el bálsamo de Gilead, también elementos minerales como el betún, cobre, el plomo y productos animales como la leche y las vísceras ${ }^{35}$.

No faltaron tampoco las intervenciones de otro tipo, sobre todo para curar la mente humana como la musicoterapia, la oniromancia, la hidromancia e incluso métodos psíquicos y psicológicos fruto de los antiguos y profundos estudios que permanecían en los «Asclepeías» guardados celosamente por los sacerdotes-médicos al servicio y culto de Asclepio, el dios griego de la medicina, y como tal, benefactor del hombre.

Así fue, pues la medicina recibida y entendida en la cultura griega como un dos de los dioses y un conocimiento científico (Tkné) una ciencia al servicio de la humanidad.

35 Ver Folch Jou, G.: Historia de la Farmacia, Madrid, 1972; Font Querr, P.: Plantas medicinales. Dioscórides renovado, Barcelona, 1976. 
Así es definida en los textos que nos ha legado los griegos para la historia:

«La medicina hace tiempo que tiene todo to que se requiere para ser un arte, pues ha descubierto un punto de partida y un método con el que se han conseguido muchos logros y valiosos descubrimientos a través del tiempo. $Y$ los demás se irán descubriendo y alcanzando en el futuro, si aquél que está capacitado conoce ya la ciencia médica y parte de ahí su investigación».

«Sobre la medicina antigua Tratados Hipocráticos, Madrid, 1990. Dir. C. García Dual.» 